\title{
The Utilization of Accelerators to Analyze Some Human Hard Tissues from Sudan
}

\author{
M. E. M. Eisa ${ }^{1,2^{*}}$, C. A. Pineda-Vargas ${ }^{3,4}$, Sami. E. E. Salah ${ }^{5}$, S. Naidoo ${ }^{6}$, J. L. Conradie ${ }^{7}$ \\ ${ }^{1}$ Department of Physics, Northern Border University, Arar, Kingdom of Saudi Arabia \\ ${ }^{2}$ Sudan University of Science \& Technlogy, Khartoum, Sudan \\ ${ }_{3}^{3}$ iThemba LABS, Materials Research Department, Somerset West, South Africa \\ ${ }^{4}$ Faculty of Health and Wellness Sciences, Cape Peninsula University of Technology, \\ Cape Town, South Africa \\ ${ }^{5}$ Faculty of Medicine, University of Al Gedarif, Al Gedarif, Sudan \\ ${ }^{6}$ Faculty of Dentistry, University of the Western Cape, South Africa \\ ${ }^{7}$ iThemba LABS, Accelerator Group, Somerset West, South Africa \\ Email: *memeisa@yahoo.com
}

Received April 18, 2013; revised May 20, 2013; accepted June 2, 2013

Copyright (C) 2013 M. E. M. Eisa et al. This is an open access article distributed under the Creative Commons Attribution License, which permits unrestricted use, distribution, and reproduction in any medium, provided the original work is properly cited.

\begin{abstract}
This study deals with an overview of the bio-medical projects performed at iThemba LABS, particularly in relation to the spatial distribution of trace metals in hard human tissues from disadvantaged Sudanese communities, such as kidney stone concretions, teeth and hair, undertaken at the iThemba LABS Nuclear Microprobe (NMP) facility. Relevant information about the ion beam techniques used for material characterization was discussed. The Particle Induced X-ray Emission (PIXE) technique was used to investigate the elemental composition of human hard tissues on a microscopic scale with the elemental mapping; complementary ion beam techniques are used to provide information on the major and minor components. Analysis of teeth sections by $\mu$-PIXE showed that the levels of trace elements were enriched and/or depleted, this may associated with leaching and/or erosive processes. On the other hand the characterization of kidney stone concretions by $\mu$-PIXE showed a marked difference of individuals from different region within Sudan.
\end{abstract}

Keywords: Nuclear Microprobe; Hard Tissues; PIXE

\section{Introduction}

Sudan lies within the tropics, the climate ranges from arid in the north to tropical wet-and-dry in the far southwest. Temperatures do not vary greatly with the season at any location; the most significant climatic variables are rainfall and the length of the dry season. Temperatures are highest at the end of the dry season when cloudless skies and dry air allow them to soar. In Khartoum the average is $21^{\circ} \mathrm{C}$ in January [1,2]. This study is a screening result of these differences in tropical climate environments, food availability, regional food habits and traditions of selected communities.

The present study concentrates on the determination of trace elements (TE) in human kidney stones, teeth and hair by nuclear microprobe (NMP) [3-5]. Interest was focused on determining levels of variability in elemental concentration of $\mathrm{Ca}$ and TE throughout selected microregions of two sets of kidney stones and another two set

\footnotetext{
"Corresponding author.
}

of teeth as well as a set of hair samples from different geographical disadvantaged communities in Sudan where the nutritional value of the daily diet is poor. The emphasis was on a comparison of regions in terms of their elemental profile content by region and to establish if a general trend in terms of elemental variability could be established based on data obtained from microanalysis by PIXE. The objective of this study to assess the concentration profiles of light elements and metals in the tooth enamel surface, kidney stones and hair by nuclear microprobe due to differences in food availability, climate, as well as regional food habits and traditions result in considerable regional variation in food consumption patterns in Sudan and similar tropical climate environments. However this work is one of the applications of the Ion beam analysis (IBA) is the most sophisticated and complete of material analysis techniques. It is based on the use of beams of particles obtained by accelerators to bombard the objects to be analysed. Particular technique used here was the Particle Induced X-ray Emission 
(PIXE) it is a technique in which a very small sample is sufficient to analyze at part per million levels by focusing the proton beam as much as possible to the target [6].

\section{Measurements}

Twelve kidney concretions from different regions of Sudan, six from the eastern region and another six from the centre of Sudan were considered for this investigation. Size of stones varied from small $(\sim 1-3 \mathrm{~mm})$ to big ( 1 $3 \mathrm{~cm}$ ). Color of stones varied from light brown to darkish gray. Clinically removed concretions were embedded in epoxy at room temperature. Cross sections through the core were cut with a diamond saw. The resulting flat surfaces were carbon coated prior to proton bombardment. Beryllium absorber $25 \mu \mathrm{m}$ thick was interposed between target and the Princeton Gamma-Tech PGT detector to reduce the high intensity Ca X-ray signals. Pile-up rejection was controlled by a beam-on-demand system, which deflected the proton beam temporarily to allow for correct digital pulse processing at high-count rates. The dominant elements as determined by PIXE were $\mathrm{Na}, \mathrm{Mg}, \mathrm{P}, \mathrm{S}, \mathrm{Cl}, \mathrm{K}, \mathrm{Ca}, \mathrm{Mn}, \mathrm{Fe}, \mathrm{Zn}$ and $\mathrm{Sr}$, using the $\mathrm{K}_{\alpha}$ line.

And another set of 12 intact teeth extracted from persons living in two different Sudanese regions were obtained from two hospitals. Most of the teeth were molars and incisors. Some had superficial early signs of decay on the enamel surface. Samples were analysed after washed with distilled water and rinsed with ethanol and allow to dry at room temperature and were embedded in resin cut cross sections was done by the with a diamond saw. Beryllium absorber $25 \mu \mathrm{m}$ thick was interposed between target and both an intrinsic high purity germanium $\mathrm{Hp}(\mathrm{Ge})$ and (PGT) detectors to reduce the high intensity $\mathrm{Ca} \mathrm{X}$-ray signals. Pile-up rejection was controlled by a beam-on-demand system, which deflected the proton beam temporarily to allow for correct digital pulse processing at high-count rates [7-9]. The dominant elements as determined by PIXE were $\mathrm{Na}, \mathrm{P}, \mathrm{Mg}, \mathrm{P}, \mathrm{S}$, $\mathrm{Cl}, \mathrm{K}, \mathrm{Ca}, \mathrm{Sc}, \mathrm{V}, \mathrm{Mn}, \mathrm{Co}, \mathrm{Cu}$ and $\mathrm{Zn}$ using the $\mathrm{K}_{\alpha}$ line. An apatite standard reference material supplied by Astimex Scientific Ltd. (Toronto) was used.

Micro-regions were scanned with a focused proton beam of 2 - $3 \mu \mathrm{m}$ spot size. True, overlap-resolved elemental maps as well as total $\mu$-PIXE data were obtained using the technique of Dynamic Analysis (DA) [10-13] implemented at the iThemba LABS NMP, together with the software package Geo-PIXE II [14]. One spot measurement of each ample was performed for the twelve kidney stones concretions, twelve teeth and ten samples of hair. Elemental concentrations of all specimens as determined by $\mu$-PIXE were submitted by SPSS analysis [13]. Figure 1 shows kidney stones plot of the SPSS for two regions. Figure 2 shows the teeth plot. Figure 3 shows the hair plot. Most of the samples are calcium rich from the graphs Ca contains approximately $80 \%$ of all the statistical information. Figure 4 showing the elemental mapping of $\mathbf{S}$ for kidney stones and Figure $\mathbf{5}$ showing the elemental mapping of Ca for teeth for two different regions and that revealing the concentrations differences of $\mathrm{S}$ and $\mathrm{Ca}$ from region to region.

\section{Results}

Here two sets of human teeth, two sets of human kidney stones Table 1, from two different geographical regions in Sudan and another two set of human hair from all over the Sudanese regions compared in terms of their $\mu$-PIXE matrix. Statistical analysis of $\mu$-PIXE data by using Statistical Package for the Social Sciences (SPSS) software package [15], they showed very great variation due to the difference in climate and diet. Trace elements S, K, Ca, Mn, Fe, Zn and Sr, were determined by $\mu$-PIXE

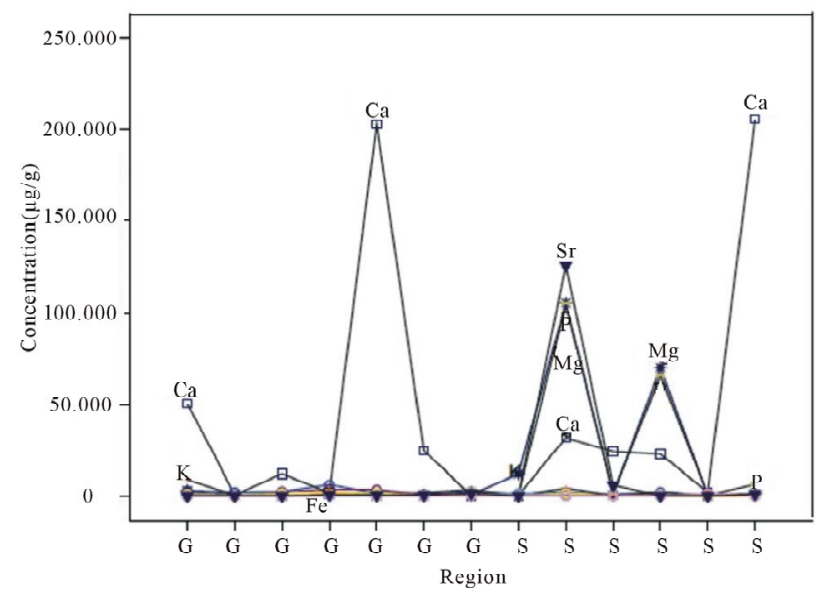

Figure 1. SPSS kidney stones analysis plot of elemental concentrations for the regions $G$ and $S$.

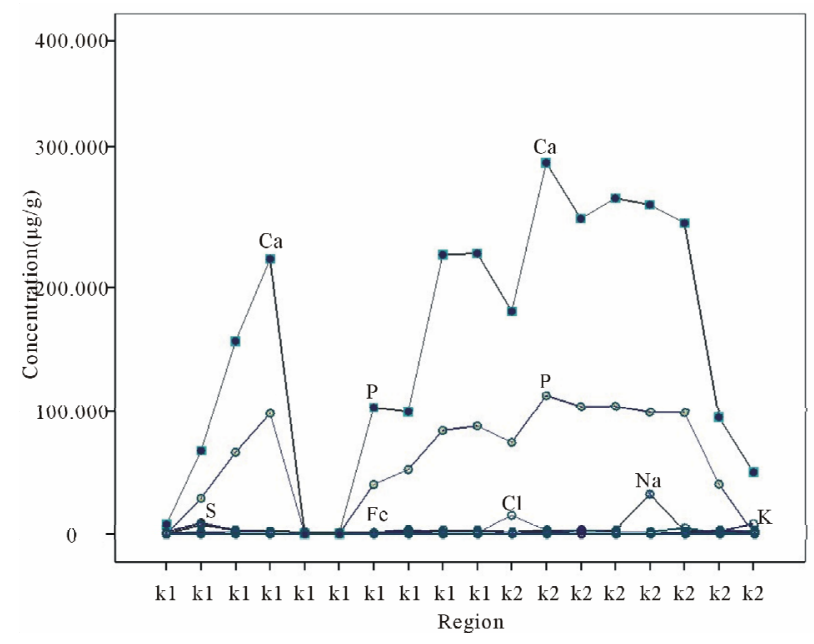

Figure 2. SPSS teeth analysis plot of elemental concentrations for the regions $K_{1}$ and $K_{2}$. 


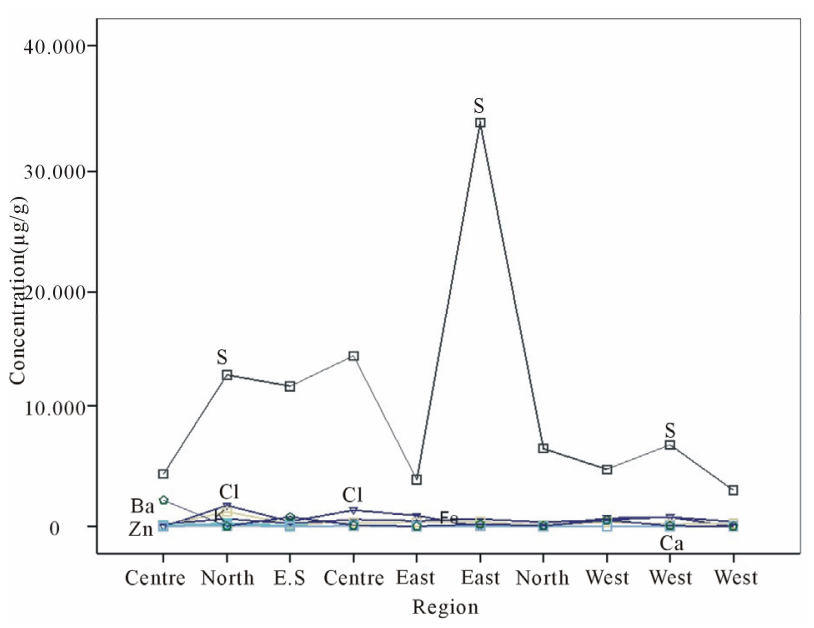

Figure 3. SPSS hair analysis plot of elemental concentrations for all over Sudanese regions.
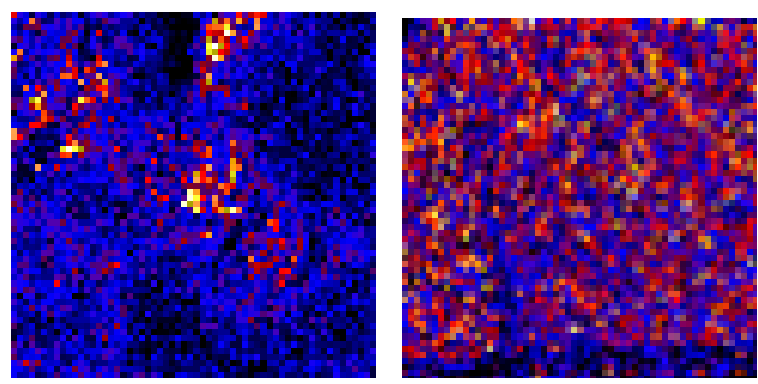

Figure 4. Maps of $S$ concentration for kidneys samples related to two different regions (East region left and centre region right).
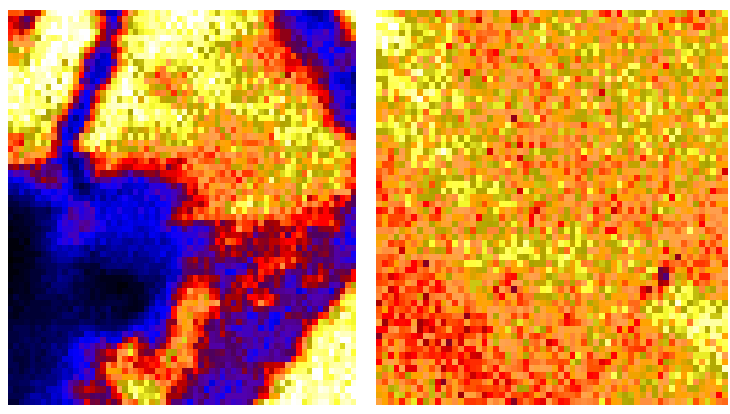

Figure 5. Maps of Ca concentration for teeth related to two different regions (East region left and centre region right).

in case of renal concretions. Their concentration levels are shown in Table 1. In general, the spatial distribution of $\mathrm{Ca}$ in most stones was non-uniform. $\mu$-PIXE results were aimed at the spatial distribution of TE, particularly, $\mathrm{Fe}, \mathrm{Zn}$ and $\mathrm{Sr}$ for both regions. In (Tables 1,2) there are variations of elemental concentrations, depletion of some of these such as $\mathrm{Zn}$ and $\mathrm{Ni}$, but the low concentration of Fe this of course due to the nutritional anemia which is among the ten major causes for hospital admission in Sudan. However, nationally representative data on iron deficiency are limited in the country. In 1995, the pre-
Table 1. Selected trace elemental concentrations of the kid-

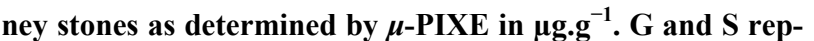
resent two different Sudanese regions; M: Male, F: Female.

\begin{tabular}{|c|c|c|c|c|c|c|c|c|}
\hline Sex & Region & & S & $\mathrm{Cl}$ & $\mathrm{Ca}$ & $\mathrm{Mn}$ & $\mathrm{Fe}$ & $\mathrm{Sr}$ \\
\hline \multirow[t]{3}{*}{ M } & G & Mean & 2816.0 & 1560.3 & 72193.7 & 111.7 & 128.3 & 285.3 \\
\hline & & $\begin{array}{l}\text { Std. } \\
\text { Dev }\end{array}$ & 649.9 & 323.2 & 113726.6 & 100.8 & 114.3 & 272.6 \\
\hline & & Rel. err. & 375.2 & 186.6 & 65660.1 & 58.2 & 66.0 & 157.4 \\
\hline \multirow[t]{3}{*}{ F } & & Mean & 663.0 & 490.5 & 18623.8 & 76.5 & 25.5 & 423.8 \\
\hline & & $\begin{array}{l}\text { Std. } \\
\text { Dev }\end{array}$ & 524.5 & 310.0 & 23867.1 & 96.3 & 51.0 & 610.2 \\
\hline & & Rel.err. & 262.3 & 155.0 & 11933.5 & 48.2 & 25.5 & 305.1 \\
\hline \multirow[t]{3}{*}{ M } & $\mathrm{S}$ & Mean & 393.6 & 567.6 & 56545.0 & 191.2 & 314.0 & 26430.4 \\
\hline & & $\begin{array}{l}\text { Std. } \\
\text { Dev. }\end{array}$ & 320.2 & 551.9 & 84172.5 & 427.5 & 627.9 & 55548.0 \\
\hline & & Rel. err. & 143.2 & 246.8 & 37643.1 & 191.2 & 280.8 & 24841.8 \\
\hline \multirow[t]{3}{*}{ F } & & Mean & 614.0 & 118.0 & 1755.0 & 0.0 & 20.0 & 0.0 \\
\hline & & $\begin{array}{l}\text { Std. } \\
\text { Dev. }\end{array}$ & $0.0^{*}$ & 0.0 & 0.0 & 0.0 & 0.0 & 0.0 \\
\hline & & Rel. err. & 0.0 & 0.0 & 0.0 & 0.0 & 0.0 & 0.0 \\
\hline
\end{tabular}

Table 2. Selected trace elemental concentrations of teeth determined by $\mu$-PIXE in $\mu \mathrm{g} . \mathrm{g}^{-1}$ representing two different Sudanese regions, K1 (North of Sudan) and K2 (Centre of Sudan). M: Male, F: Female. Elements of zero concentrations means they are under the detection limit of the $\mathrm{Nu}$ clear Microprobe system (NMP).

\begin{tabular}{|c|c|c|c|c|c|c|c|}
\hline Sex & Region & & K & $\mathrm{Ca}$ & $\mathrm{Mn}$ & $\mathrm{Fe}$ & $\mathrm{Zn}$ \\
\hline \multirow[t]{6}{*}{ M } & K1 & Mean & 1048 & $1 E+05$ & 157.0 & 177.7 & 227.7 \\
\hline & & Std. Dev & 519.2 & 92878 & 235.10 & 117.1 & 174.8 \\
\hline & & Rel. err. & 259.6 & 46439 & 117.5 & 58.5 & 87.40 \\
\hline & K2 & Mean & 2773 & $2 E+05$ & 444.2 & 102 & 107.5 \\
\hline & & Std. Dev. & 3830 & $1 E+05$ & 298.7 & 80.5 & 88.2 \\
\hline & & Rel. err. & 1915 & 53667 & 149.3 & 40.2 & 44.1 \\
\hline \multirow[t]{6}{*}{ F } & K1 & Mean & 685.1 & $1 E+05$ & 379.4 & 104.1 & 171.8 \\
\hline & & Std. Dev. & 405.8 & 96335 & 319.4 & 44.8 & 223.3 \\
\hline & & Rel. err. & 153.4 & 36411 & 120.7 & 16.9 & 84.4 \\
\hline & K2 & Mean & 1537 & $2 E+05$ & 36.6 & 205.3 & 80.6 \\
\hline & & Std. Dev. & 602 & $1 E+05$ & 63.5 & 62.2 & 139.7 \\
\hline & & Rel. err. & 347.6 & 62622 & 36.6 & 35.9 & 80.6 \\
\hline
\end{tabular}

valence of anemia (defined as hemoglobin $<11.0 \mathrm{~g} / \mathrm{dL}$ ) in children under five years was very high. Almost all of the regions surveyed showed more than $80 \%$ of children were anemic. In Khartoum the prevalence was the lowest but affected almost one third of children [16]. In 2004, in the crisis-affected population of Darfur, the prevalence of anemia was $55 \%$. Severe anemia affected more than $1 \%$ of children. Nationally representative data on iron deficiency is limited in the country. In 1995, the prevalence of anemia (defined as hemoglobin $<11.0 \mathrm{~g} / \mathrm{dL}$ ) in children under five years was very high, and in almost all states surveyed, more than $80 \%$ of children were anemic [16]. High concentration levels of Ca in some of 
the regions due to the diet way from region to region.

\section{Conclusion}

Accelerator energy of $3 \mathrm{MeV}$ has been successfully used for the analysis of this disadvantaged communities, it is due to differences in food availability, climate as well as regional food habits in Sudan. The $\mu$-PIXE analysis result showed marked differences between different regions in elemental concentration. Figure $\mathbf{4}$ are selected maps from east and centre which showed great differences in elemental mapping between the two regions for the elements $\mathrm{S}$ in kidney stones, $\mathrm{Ca}$ in teeth and $\mathrm{K}$ in hair the difference here due to many factors such as diet, food consumption patterns, water and the environment. Information on the major components showed marked differences due. On the other hand quantitative $\mu$-PIXE results showed a significant depletion and/or increase in some trace elements, particularly $\mathrm{Fe}, \mathrm{Ni}, \mathrm{Cu}, \mathrm{Zn}$ and $\mathrm{Sr}$ for most of the samples in all regions this including (stones, teeth and hair). In case of depletion of $\mathrm{Fe}$ as mentioned by the report of FAO this is due to the deficiency of Fe in most of the Sudanese regions. In relation to the study of teeth, the main conclusion is that in spite of the high variability of the trace elements concentration, the mean values appear to be smaller and different for all (male, female).

\section{Acknowledgements}

The authors would like to thank the staff of the Materials Research Department at iThemba LABS for their support throughout the experiments and measurements, TWASUNESCO for their support, Sudan University of Science \& Technology for the financial support and encouragement and Dr. R.Rossouw from University of Western Cape for his great help of preparing the samples.

\section{REFERENCES}

[1] R. Pankhurst, “The Ethiopian Borderlands,” Red Sea Press, Lawrenceville, 1997.

[2] C. M. Hogan, "Painted Hunting Dog: Lycaon Pictus," GlobalTwitcher.com, 2009.

[3] C. A. Pineda and M. Peisach, "Micro-Analysis of Kidney Stones Sequentially Excreted from a Single Patient," $\mathrm{Nu}$ clear Instruments and Methods in Physics Research Section B: Beam Interactions with Materials and Atoms, Vol. 85, No. 1-4, 1994, pp. 896-900. doi:10.1016/0168-583X(94)95945-5

[4] C. A. Pineda, A. L. Rodgers, V. M. Prozesky and W. J. Prybylowicz, "Microanalysis of Calcium-Rich Human Kidney Stones at the NAC Nuclear Microprobe," Cell and Molecular Biology, Vol. 42, No. 1, 1996, pp. 119-126.

[5] C. A. Pineda-Vargas, A. L. Rodger and M. E. Eisa, "Nuclear Microscopy of Human Kidney Stones, Comparison between Two Population Groups,” Radiation Physics and
Chemistry, Vol. 30, No. 3, 2004, pp. 947-950. doi:10.1016/j.radphyschem.2004.04.125

[6] D. Ronald, "The Proton Microprobe Applications in the Biomedical Fields,” CRC Press, Boca Raton, 2000.

[7] W. J. Przybylowicz, J. Mesjasz-Przybylowicz, C. A. Pineda, C. L.Churms, C. G. Ryan, V. M. Prozesky, R. Frei, J. P. Slabbert, J. Padayachee and W. U. Reimold, "Elemental Mapping Using Proton-Induced X-rays," $X$ ray Spectrometry, Vol. 30, No. 3, 2001, p. 156. doi:10.1002/xrs.474

[8] V. M. Prozesky, C. A. Pineda, J. Mesjasz-Przybylowicz, W. J. Przybylowicz, C. L. Churms, K. A. Springhorn, Ph. Moretto, C. Michelet, U. Chikte and P. Wenzel, “The Biological Research Programme of the Nuclear Microprobe at the National Accelerator Centre, Faure," $\mathrm{Nu}$ clear Instruments and Methods in Physics Research Section B: Beam Interactions with Materials and Atoms, Vol. 161-163, 2000, pp. 852-859.

doi:10.1016/S0168-583X(99)00895-2

[9] C. A. Pineda-Vargas, S. Naidoo and M. E. M. Eisa, “Nuclear Microanalysis of Tooth Enamel from a Community in the Western Cape, South Africa," Nuclear Instruments and Methods in Physics Research Section B: Beam Interactions with Materials and Atoms, Vol. 260, No. 1, 2007, pp. 190-193. doi:10.1016/j.nimb.2007.02.023

[10] C. G. Ryan, E. Van Achterbergh and C. J. Yeats, T. T. Win and G. Cripps, "Quantitative PIXE Trace Element Imaging of Minerals Using the New CSIRO-GEMOC Nuclear Microprobe," Nuclear Instruments and Methods in Physics Research Section B: Beam Interactions with Materials and Atoms, Vol. 189, No. 1-4, 2002, pp. 400-407. doi:10.1016/S0168-583X(01)01098-9

[11] C. G. Ryan, "Quantitative Trace Element Imaging Using PIXE and the Nuclear Microprobe,” International Journal of Imaging Systems and Technology, Vol. 11, No. 4, 2000, pp. 219-230. doi:10.1002/ima.1007

[12] C. G. Ryan, E. van Achterbergh, C. J. Yeats, S. L. Drieberg, G. Mark, B. M. McInnes, T. T. Win, G. Cripps and G. F. Suter, "Quantitative, High Sensitivity, High Resolution, Nuclear Microprobe Imaging of Fluids, Melts and Minerals," Nuclear Instruments and Methods in Physics Research Section B: Beam Interactions with Materials and Atoms, Vol. 188, No. 1-4, 2002, pp. 18-27. doi:10.1016/S0168-583X(01)01003-5

[13] C. A. Pineda-Vargas and M. E. M. Eisa, "Analysis of Human Hair Cross Sections from Two Different Population Groups by Nuclear Microscopy," Nuclear Instruments and Methods in Physics Research Section B: Beam Interactions with Materials and Atoms, Vol. 268, No. 11-12, 2010, pp. 2164-2167. doi:10.1016/j.nimb.2010.02.041

[14] C. G. Ryan and D. R. Cousens, "Geo-PIXE II Quantitative PIXE Trace Element Imaging and Analysis,” CSIRO Exploration and Mining, North Ryde, 2002

[15] SPSS, "Data Analysis Software System, Version 15," 2006. www.spss.com.

[16] FAO, "Sudan Nutrition Profile-Food and Nutrition Division,” 2005. 